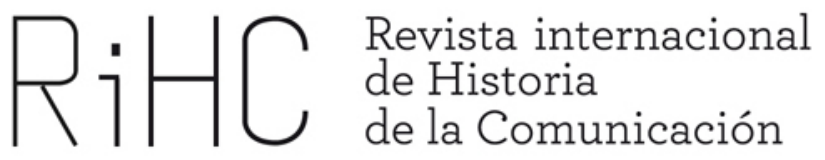

\title{
LA NACIÓN Y EL SINDICALISMO EN 1983: LA CRISIS, LAS HUELGAS Y LA DEMOCRATIZACIÓN ${ }^{1}$
}

La Nación and trade unionism in 1983: the crisis, strikes and democratization

DOI: http://dx.doi.org/10.12795/RiHC.2017.i09.04

César Luis Díaz

Universidad Nacional de La Plata

tatodiaz60@gmail.com

Mario Jorge Giménez

Universidad Nacional de La Plata

mariojgimenez@yahoo.com.ar

aceptado: $11-9-2017$

recibido: 13-12-2017

Resumen: En el presente artículo se examina la posición editorial sostenida por La Nación uno de los diarios más antiguos de la Argentina. Exponente del pensamiento

\footnotetext{
${ }^{1}$ Este trabajo forma parte del proyecto de investigación "La agenda editorial de los socios en las postrimerías de la dictadura militar (1982-1983)”, dirigido por el Dr. César Luis Díaz.
} 
liberal confrontó con las políticas estatistas del peronismo, así como también con la sindicalización masiva de trabajadores ocurrida en el decenio 1945-1955, posicionamiento que mantendría hasta el tercer gobierno justicialista. A este último, tanto como a las organizaciones armadas y al sindicalismo los responsabilizaría de la crisis del país, propiciando el golpe cívico militar de 1976y la legitimación del terrorismo de Estado para restaurar el "orden". Desde entonces, avaló la intervención a los gremios y silenció la desaparición y el presidio de centenares de dirigentes sindicales. Después de la derrota en las Malvinas el 14 de junio de 1982, comenzaría la transición hacia la democracia en el país. Entonces, el matutino examinado, a pesar de reconocer la crisis económica y social existente, destinaría una importante cantidad de editoriales para fustigar las medidas de fuerza ejecutadas por los sindicatos y las centrales obreras, acusándolos de actuar por intereses personales, partidistas y hasta subversivos que terminarían atentando no sólo contra el proceso de democratización, sino contra la convivencia social.

Palabras clave: Diario, La Nación, sindicalismo, transición democrática, 1983

\begin{abstract}
This article examines the editorial position held by La Nacion, one of the oldest newspapers in Argentina. An exponent of liberal thinking confronted with the statist policies of Peronism, as well as with the massive unionization of workers that occurred in the 1945-1955 decade, a position that would maintain the Third Peronist government. The latter, as well as armed organizations and trade unionism, would hold them accountable for the country's crisis, propitiating the 1976 military coup and legitimizing state terrorism to restore "order." Since then, he endorsed the intervention of the guilds and silenced the disappearance and imprisonment of hundreds of trade union leaders. After the defeat in the Malvinas on June 14, 1982, the transition to democracy in the country would begin. Thus, despite the recognition of the existing economic and social crisis, the newspaper examined a large number of publishers to attack the measures of force carried out by the trade unions and the workers' organizations, accusing them of acting for personal, partisan and even subversive interests, would end up attacking not only the process of democratization, but against social coexistence.
\end{abstract}

Keywords: Journal, La Nación, trade unionism, democratic transition, 1983

\title{
1 Introducción y metodología
}

En los tiempos que corren, nadie puede poner en duda que los medios de comunicación se han vuelto omnipresentes en la vida cotidiana de la sociedad. De este modo, tanto los actores que participan en las más encumbradas esferas del poder político, económico y social como los ciudadanos en general no pueden mantenerse ajenos a su incidencia. 
En nuestro caso, dedicados desde hace décadas al estudio de los medios gráficos en la Argentina, si bien no podríamos afirmar que su lugar en la sociedad pretérita sea equiparable al que cumplen hoy los medios masivos, sí podemos sostener que los diarios han sido, y aún son, particularmente apreciados por las élites que toman las decisiones que modifican el rumbo del país, sobre todo si hablamos de La Nación ${ }^{2}$ en la Argentina. En esta oportunidad, estudiamos su discurso editorial sobre el sindicalismo en la transición a la democracia actual, es decir, desde el 1 de enero hasta el 30 de octubre de 1983, momento en el cual la ciudadanía pudo elegir un presidente constitucional, después de más de siete años de dictadura. Aquella coyuntura se convirtió entonces en un punto de inflexión en la vida institucional de nuestro país, pues abrió paso a un periodo de treinta y cuatro años sin interrupción de los gobiernos constitucionales votados libremente por la ciudadanía. Esta circunstancia, y el desafío que implicaba para el sindicalismo ejercer la defensa de los derechos de los trabajadores en aquella coyuntura signada por una triple crisis: económica, social e institucional, dan cuenta de la relevancia de examinar la percepción que el diario tenía de este actor.

En este artículo, nos centramos en la mirada valorativa que se expresó en la estrategia discursiva del diario sobre algunos aspectos de la situación social de los trabajadores y las medidas de fuerza que protagonizaron los sindicatos que los representaban. Al respecto, se debe tener en cuenta que el ni el recorte del objeto de indagación ni el recorte temporal de su actuación cuentan con una prolífera producción bibliográfica.

Nuestra hipótesis de trabajo propone corroborar si la ponderación negativa que realizó La Nación sobre el protagonismo sindical, por considerarlo contrario a la República y la vida institucional del país desde principios del siglo $X X$, se sostuvo como posición constante en la transición a la democracia de 1983. Cabe mencionar que esta línea editorial se agudizó particularmente con la aparición del peronismo a mediados de la década de 1940 y en 1976 lo impulsó a apoyar un golpe que, en su plan de restauración del "orden", le otorgó prioridad a la transformación de este actor.

\footnotetext{
${ }^{2}$ El 4 de enero de 1870 nacía esta página periódica bajo la dirección del ex presidente de La Nación Bartolomé Mitre, quien anunció en su primer número que el diario sería una "tribuna de doctrina" del liberalismo vernáculo. No obstante, esto se materializaría recién en 1909 tras la muerte del último Mitre que aspiró a ser presidente de la Argentina. Esta centenaria hoja supo interpretar los intereses de los sectores tradicionales vinculados a las familias que conformaban la burguesía agroexportadora. En efecto, los individuos que se encontraban en las posiciones más altas de la estructura del poder político, del sistema económico y de la jerarquía del reconocimiento social, compartían el hábito de la lectura de sus páginas, característica que continuó vigente en la etapa indagada y, aún, en la actualidad. Recordemos que este pacto de lectura que se establece entre el medio y su lector ante el acto de comprar un diario importa "un acto ritual, porque es adquirir una matriz de decodificación de los hechos sociales que organiza la realidad que al mismo tiempo construye. Mediante ellas al lector se le ofrecen formas de ver el mundo social. La fidelidad para con un diario puede llegar a ser mayor que para otros objetos igualmente familiares" (Sidicaro, 1993: 7).
} 
El análisis del corpus se efectúa desde la perspectiva de la historia del periodismo, reconociendo el carácter de actor político del diario (Borrat, 1989) y la relevancia del editorial, en la medida que este representa la voz institucional del medio. La singularidad de su construcción discursiva radica en que se dirige principalmente a quienes toman las decisiones, así como también lo hace ante todos los actores de la sociedad ejerciendo su poder de legitimación. Para ello se vale de diversos artilugios, pues "a diferencia de los códigos artificiales, los lenguajes humanos proveen recursos para expresarse en forma vaga, para hacer entender lo que no se dijo y para dejar abierta la posibilidad de retractarse de lo dicho [...]. En ninguna sociedad conocida en el mundo existe una libertad total e igualitaria para el tratamiento verbal de cualquier tópico. En todas hay temas tabú, que son peor o mejor recibidos. La forma más definitiva de eludirlos es no plantearlos pero, dentro de la mención, las distintas lenguas poseen recursos lingüísticos de diverso grado de sutileza que permiten regular el carácter de lo dicho" (Lavandera, 2014: 291). En este caso, consideraremos la conceptualización planteada por C. Kerbrat-Orecchioni en relación con los "subjetivemas" que constituyen las enunciaciones del diario producidas en el particular contexto del fin de ciclo de la dictadura y la inminencia de la restauración democrática, atendiendo a que "toda unidad léxica es, en un cierto sentido, subjetiva, dado que las 'palabras' de la lengua no son jamás otra cosa que símbolos sustitutivos e interpretativos de las 'cosas'" (1997: 91-92, el destacado es de la autora). De acuerdo con su carga valorativa, estos "subjetivemas" son clasificados por la investigadora en afectivos y evaluativos, siendo a su vez estos últimos divididos en axiológicos y no axiológicos. ${ }^{3}$ Asimismo, atenderemos a las figuras utilizadas, ${ }^{4}$ los pares antagónicos, asociaciones alrededor de un término (enlaces positivos), ${ }^{5}$ la metáfora organicista, ${ }^{6} \mathrm{y}$ el uso de ciertas palabras clave en la formulación de los editoriales.

\footnotetext{
${ }^{3}$ Kerbrat-Orecchioni sostiene que los subjetivemas afectivos son los que al mismo tiempo enuncian una propiedad del objeto y una reacción emocional del sujeto frente a ese objeto, mientras que los evaluativos se dividen en dos tipos según el nivel de evaluación que realizan: los no axiológicos, que no realizan necesariamente juicio de valor o compromiso afectivo por parte del locutor pero sí implican una evaluación cualitativa o cuantitativa del objeto, y los axiológicos, que aplican al objeto un juicio de valor positivo o negativo y se los considera doblemente subjetivos. Por un lado, su uso varía según la naturaleza del sujeto de la enunciación (reflejan su competencia ideológica); por otro, manifiestan una toma de posición a favor o en contra del objeto (1997: 111-123-el destacado es nuestro-).

${ }^{4}$ O. Ducrot (1989: 149) presenta tres figuras: "el principio de autoridad intercalado en la exposición de un argumento, permite deducir una conclusión de ese argumento mismo sin necesidad de demostrar su verdad, la ironía opera del mismo modo pero en sentido inverso. Para demostrar que una tesis es falsa se utilizan a favor de ella argumentos absurdos que se atribuyen a defensores de esa tesis (...) y la concesión: siguiendo una estrategia esencial al liberalismo concede la palabra a un adversario real o ficticio aunque argumente en dirección opuesta para reforzar la imagen de objetividad de nuestra propia conclusión".

${ }^{5}$ Consideraremos "pares antagónicos" a "los antónimos que van por parejas complementarias (...) constituyendo pares originales que un análisis contrastativo debe destacar" y "enlaces positivos" a las "relaciones sintagmáticas que no alcanzan el status de sinónimos" (Maingueneau, 1989: 66 -67).

${ }^{6}$ Francisco Delich (1983: 11-31).
} 
El trabajo se desarrolla en tres capítulos: el primero destinado a reconocer el posicionamiento del diario en relación con los lineamientos centrales de la política de la dictadura y particularmente señalar de qué forma el sindicalismo y los trabajadores se convirtieron en sus víctimas entre 1976 y 1982, plan represivo que contó con el beneplácito de La Nación quien consideraba que a la vigencia de los derechos laborales y el accionar de los sindicalistas debían limitarse porque habían contribuido con la crisis institucional antes del golpe de Estado de 1976. En segundo término se da cuenta de cómo a comienzos de 1983 el diario examinado reconocía la existencia de una crisis económica, a pesar de que divergía tanto con las medidas propuestas por las autoridades para paliar sus efectos, cuanto con el accionar de los sindicalistas cuyas medidas de fuerza "perjudicaban" a terceros. En tercer lugar se consideran las notas en las que el matutino sostiene que el perjuicio ocasionado por la acción sindical atenta contra el proceso de democratización del país y la propia integridad de la sociedad.

\section{La Nación y la restauración del orden entre 1976 y 1982}

A comienzos de 1976, la Argentina se encontraba en una situación de crisis generalizada que atravesaba todos los ámbitos de la vida nacional. Las pautas programáticas expuestas en las elecciones de 1973, que le dieron un amplio triunfo al Frente Justicialista de Liberación (FREJULI), fueron abandonadas a posteriori de la muerte del presidente Juan D. Perón, el 1 de julio de 1974. La acefalía de liderazgo que produjo su deceso se pudo apreciar tanto en el plano institucional como en el interior de la fuerza política gobernante. De este modo, los distintos actores sociales, políticos y económicos que contribuyeron a su ascenso, entre ellos el movimiento obrero, a partir de esa fecha se centraron en disputas por el poder y la apropiación de la renta, contribuyendo con el debilitamiento del Poder Ejecutivo encabezado por María Estela Martínez. En este escenario, recuperaron rápidamente su dinamismo otros actores, tales como los miembros de la alta burguesía industrial y agropecuaria vinculados con el mercado externo y las Fuerzas Armadas, quienes volvieron a coincidir en la necesidad de destituir al gobierno elegido por el voto popular y reemplazarlo por una dictadura cívico-militar. Esta decisión contó con la ostensible contribución del conjunto de los medios gráficos, entre ellos el diario La Nación, los cuales participaron en la construcción discursiva del golpe de marzo de 1976. El matutino que examinamos hizo su aporte mediante la polisémica figura del "gran cambio", que en aquella coyuntura era propuesta para impedir el supuesto desbarrancamiento del país hacia el comunismo al cual contribuían el gobierno peronista, las organizaciones armadas y el 
sindicalismo (Díaz, Giménez, Passaro, 2002). Por esta razón, el diario no dudará en avalar el terrorismo de Estado, inspirado en la doctrina de Seguridad Nacional, ejerciendo un "periodismo hermesiano" (Díaz, 2011) mediante el cual, en defensa de los principios del "ser nacional" sustentado en la "civilización occidental y cristiana", amplificaba el discurso castrense y justificaba la eliminación de los disidentes.

Esta sociedad ideológica será refrendada en el plano económico en mayo de 1977, cuando La Nación junto a La Razón y Clarín se conviertan en socios del Estado dictatorial en la empresa Papel Prensa S.A., vínculo comercial que a su vez será consolidado desde la sección institucional al azuzar a los mandantes castrenses a que produzcan transformaciones irreversibles en el plano normativo y mediante la represión directa del accionar, en el caso que nos ocupa, de las organizaciones gremiales ${ }^{7}$. Así pues, cuando centenares de militantes sindicales sufrían la desaparición forzada ${ }^{8}$ y muchos dirigentes y activistas eran encarcelados y solamente unos pocos lograban exiliarse, La Nación no escatimaba el uso de subjetivemas negativos para descalificar al sindicalismo, deslegitimándolo como actor político al atribuirle demagogia, corrupción, excesos, vicios e intereses mezquinos; y en el mismo sentido, mencionándolo a través de los siguientes enlaces positivos: vieja dirigencia, compulsiva, personalista, subcaudillos, cacicazgo altamente remunerado, máquina de extorsión grosera o agresivos, con el indudable cometido de producir un efecto nocivo en el imaginario colectivo sobre este actor político (Díaz, Giménez, 2016). La desvalorización discursiva del diario La Nación sobre las medidas de acción directa impulsadas por el sindicalismo puede apreciarse en la opinión editorial publicada sobre la Jornada Nacional de Protesta del 19 de abril de 1979, organizada por el Grupo de los $25^{9}$. Esta medida, la primera de oposición general a las políticas del dictador Jorge Videla y su ministro de Economía José Martínez de Hoz fue menoscabada por el matutino pues la atribuía a pujas personales entre los convocantes como parte de "la

\footnotetext{
7 Al respecto, Fernández Berdaguer $(2007,184)$ sostiene: "El gobierno militar del proceso de reorganización nacional se propuso reestructurar el papel de los sindicatos. En este sentido operó la eliminación de la negociación colectiva y, más importante aún, la aplicación de diversos mecanismos no solo económicos- que redujeron fuertemente la capacidad de reacción del movimiento obrero". Por su parte, Diéguez y Gerchunoff $(1984,24)$ puntualizan “es necesario considerar el clima que predominó, ya que la política de contracción salarial se realizó en un contexto represivo y persecutorio, con la intervención de los sindicatos, despidos, detención, secuestro de dirigentes gremiales, supresión del funcionamiento de comisiones paritarias, modificaciones de convenios colectivos de trabajo y control de actividad gremial aún a nivel de fábrica y unidades de trabajo".

${ }^{8}$ El registro de la CONADEP señala que "el 30,2\% de los detenidos-desaparecidos denunciados en la Comisión Nacional sobre la Desaparición de Personas son obreros, y el 17,9\%, empleados (del $21 \%$ que representan los estudiantes, uno de cada tres trabajaba)". Aunque resulta interesante reparar que de acuerdo al desagregado que ofrece un gráfico incluido en la misma obra se podrían sumar las siguientes víctimas: "docentes 5,7\%, periodistas 1,6\%" con lo cual, solo los trabajadores superarían más de la mitad de los desaparecidos (CONADEP, 2012: 300 y 378).

${ }^{9}$ Constituido en marzo de 1977 por la autoconvocatoria de dirigentes pertenecientes a ese número de sindicatos, destacándose entre otros el cervecero Saúl Ubaldini.
} 
lucha interna que se libra en el sindicalismo por la dirección de sus actividades" $(26 / 4 / 79)$ y no a la defensa de los intereses de los trabajadores. También el paro general convocado por la CGT Brasil ${ }^{10}$ para el 22 de julio de 1981, durante la presidencia del segundo dictador general Roberto Viola, será cuestionado por el diario, en este caso aplicando el principio de autoridad de la historia al afirmar: "de acuerdo con la experiencia argentina, paros y huelgas han sido tal vez el factor que en mayor medida inhibió la libre discusión en el seno de las paritarias" (18/7/81). Por supuesto que en esta nota, omitía mencionar en el artículo que el instituto de las paritarias que permitían a trabajadores y empleadores discutir y acordar condiciones laborales bajo la observación del Estado había sido anulado por la dictadura.

En diciembre de 1981, cuando el general Leopoldo F. Galtieri expulsó a su colega R. Viola de la Casa Rosada poniendo en evidencia la siempre latente puja interna en el ejército al traicionar los postulados del llamado Proceso de Reorganización Nacional (PRN), La Nación habló de la "crisis moral del proceso"11. No obstante, la postergación de la democratización del país enunciada por el tercer dictador y el retorno a los postulados económicos del liberalismo ortodoxo de 1976, anunciados por el ministro de Economía Roberto Alemann, alentarían las esperanzas del diario sobre el renacimiento del PRN. Ambas decisiones, acrecentarían la conflictividad sindical que se vio expresada en la histórica movilización protagonizada por la CGT Brasil el 30 de marzo de 1982. En esta ocasión, el gobierno respondería con la represión de los manifestantes en la Capital Federal y varias capitales provinciales logrando centenares de activistas y dirigentes presos, heridos y hasta un muerto a manos de la policía de la provincia de Mendoza. Tres días después, la recuperación de las Malvinas será valorada por el matutino examinado como un hecho histórico decisivo en pos de alcanzar una "unidad nacional" coaligando a militares y civiles a quienes confrontaba, como par antagónico, con el "sectarismo" de los sindicalistas y el peronismo. Así, La Nación propugnaba que la gesta del Atlántico Sur se convirtiera en un punto de inflexión histórico para que el país recupere la democracia y la república marginando a dos actores centrales de la vida institucional argentina desde 1945: el sindicalismo y el peronismo (Giménez, 2015). Una vez concluida la contienda bélica, estas expectativas se esfumaron y la deslegitimación del sindicalismo en la columna institucional continuó sin solución de continuidad, volviendo a transitar por una estrategia discursiva "hermesiana". En efecto, ante el anuncio de la CGT Brasil sobre la realización de un paro de actividades para el día 6 de diciembre y la movilización a la cual convocaba la Comisión Multipartidaria a la Plaza de Mayo diez días después, el matutino decidió vincular ambos eventos en una nota titulada: "El derecho de peticionar". En ella, si bien reconocía la legitimidad de ejercitar ese derecho, cuestionaba a los sindicalistas

\footnotetext{
${ }^{10}$ La CGT Brasil, cuyo antecedente era el Grupo de los 25, se conformó el 12 de diciembre de 1980. Su primer secretario general fue S. Ubaldini (Abós, 1984: 75).

11 “Hora de incertidumbre y desaliento”, La Nación, 10-12-1981, p. 8.
} 
por "la politización del reclamo gremial" ${ }^{12}$ y la posibilidad de que el paro y la movilización pudieran incurrir en el delito de "sedición y subversión" (4/12/82). Ambos términos, frecuentes en esta columna poco antes de quebrarse el orden institucional en 1976 y también durante los primeros años de la dictadura, aparecían dirigidos a instalar un imaginario negativo sobre el protagonismo sindical en la etapa de transición hacia la democracia (Díaz, Giménez, 2016).

\section{La crisis en 1983: las medidas dictatoriales y los prejuicios del accionar sindical}

A poco de comenzar el año de la transición a la democracia argentina, La Nación evidenciaba una preocupación poco habitual en su columna institucional sobre ciertos efectos de las políticas económicas dictatoriales difíciles de invisibilizar. Por caso, en el editorial titulado "Ollas populares"13 hacía notar, mediante el empleo de subjetivemas evaluativos no axiológicos que "las penosas condiciones sociales imperantes en no pocos sectores" (5/1/83) les imponían concurrir a esos comedores callejeros improvisados para mitigar su hambre. El fenómeno que motivó esta columna institucional no solo se desentendía de explicar las causas de las "penosas condiciones sociales", sino que además no volvió a ser retomada en el resto del lapso examinado.

Al respecto, debe tenerse en cuenta la incesante pérdida de fuentes laborales provocada desde 1976 por de la aplicación del plan económico de Martínez de Hoz (Schvarzer 1998:34) que dejó a miles de trabajadores desocupados y alcanzó hacia 1983 ribetes alarmantes. Esta situación sería jerarquizada editorialmente por el matutino de los Mitre cuando el PEN dejara trascender que adoptaría medidas para paliar esa situación. Su columna no tenía otro cometido que el de polemizar con la iniciativa gubernamental destinada a otorgar "El subsidio a los desocupados" ${ }^{14}$. La

\footnotetext{
${ }^{12}$ Godio y Palomino (1988: 53) interpretan que "desde mediados de 1982 el sindicalismo desarrolló una activa movilización social aprovechando la descomposición del régimen, y con el objetivo de recuperar los niveles salariales fuertemente deteriorados durante la guerra debido al congelamiento de salarios impuesto por el ministro de Economía de Galtieri, y a la prosecución de la inflación en ese periodo. Una oleada de conflictos laborales en demanda de mejoras salariales, y como manifestaciones de repulsa al régimen que se derrumbaba, fue colocando a los dirigentes sindicales en el centro de la escena política y social".

13 “Ollas populares”, La Nación, 5-1-1983, p. 6.

14 “El subsidio a los desocupados”, La Nación, 19-1-83, p. 8.
} 
misma, acordada con la cúpula de la CGT Azopardo ${ }^{15}$ consistía en una asistencia financiera por el término de seis meses destinada tan solo a quienes quedaron en esa situación entre enero y noviembre de 1982. El editorial, como si ignorara lo que el mismo diario informó once días atrás, omitía mencionar que la iniciativa surgió merced a una gestión de la central obrera citada con lo cual evitaba reconocer su comportamiento propositivo y acuerdista con las autoridades. Otra elisión respecto de su cobertura informativa radicó en el cuestionamiento efectuado a los ministros de Acción Social y Trabajo, quienes, sostenía en la columna editorial, la habían pergeñado sin conocimiento del titular de la cartera de Economía. En distinto orden, rechazaba que excluyera de sus beneficios a quienes habían perdido su trabajo antes del periodo considerado. Por su parte, propondría una alternativa que, si bien en su concepto no morigeraba el error de concepción del gobierno de facto, sin duda respondía al contrato de lectura (Verón, 2005:199) establecido con su público fuertemente ligado a la producción agropecuaria. En razón de ello, ponía en evidencia el contraste que ofrecía el sistema productivo argentino con miles de desocupados industriales a la vez que faltaban brazos para las labores agrícolas. Para corregir la "distorsión", señalaba admonitoriamente al poder ejecutivo que destinara el subsidio a quienes estuvieran dispuestos a realizar esas faenas utilizándolo para trasladarse hasta los lugares correspondientes. Así, sus afirmaciones nos permiten hacernos una idea cabal de cuál era el concepto que construían sus enunciados sobre la vida del trabajador y, por ende, de su calificación, trayectoria e idoneidad, en este caso el urbano, que era el que sufría en mayor medida los efectos de la desindustrialización y la importación de manufacturas. En su criterio, una persona que se quedaba sin trabajo tendría que ser capaz de desempeñarse en cualquier tarea, aunque esta se ejecutara a varios kilómetros de su residencia y no tuviera relación alguna con su capacitación. Resulta elocuente que la sensibilidad puesta de manifiesto ante los concurrentes a las ollas populares, no se evidenciara ante el desarraigo que implicaba para un trabajador dejar a su familia y afectos, sus hábitos urbanos, sus pautas de trabajo y sus derechos adquiridos durante años de sindicalización. El remate de la columna tomaba como principio de autoridad al presidente del Banco Central, develando otra preocupación en torno a cómo paliar la desocupación y resaltando, mediante subjetivemas

\footnotetext{
${ }^{15}$ Corresponde mencionar que el diario el 8 de enero anunció en la parte superior izquierda de la tapa, a cuatro columnas en dos líneas con letras de gran porte: "Acordose el subsidio para los desocupados", detallando que "en el curso de la semana el acuerdo a que arribaron los ministros [de Trabajo, Acción Social y Economía]será expuesto a la dirigencia de la CGT-Azopardo que reclamó la vigencia de esa medida", mientras que en página 5 el ministro de Trabajo informó que el "gabinete económico y social se reunirá con la cúpula de la CGT Azopardo "para cambiar ideas respecto del sistema a implementar". Además, el 12 de enero también en tapa con similares características que en la anterior portada pero en la parte superior derecha, donde el impacto visual es mayor, titulaba "Elevan esta semana el proyecto del subsidio" y en el desarrollo de la nota daba cuenta de algunos de los tópicos que le fueron informados a los cuatro miembros del secretariado de la CGT Azopardo: Jorge Triaca (trabajadores plásticos), Raúl Baldassini (trabajadores telepostales), Jorge Luján (Sindicato del Vidrio) y Luis Etchezar (La Fraternidad-maquinistas ferroviarios-).
} 
axiológicos negativos, que el nuestro era "un país en el que se ha gastado sin ton ni son" ${ }^{16}$ y que esta medida, cualquiera fuera el destino de los fondos que se invirtieran, se convertiría a la postre en un problema financiero para un país que se estaba ordenando para lograr el apoyo del FMI. Una vez puesta en vigencia la misma, La Nación publicó otro artículo ${ }^{17}$ en el cual volvió a insistir en su preocupación por el financiamiento de la propuesta, pues consideraba mediante subjetivemas axiológicos negativos que la creación de un impuesto a los depósitos a plazo fijo (al cual apelaban quienes tenían un ingreso que se lo permitía para no perder el valor de sus ahorros) constituía un "peligroso antecedente". Entretanto, para evitar que los subsidiados se mantuvieran inactivos, quizás porque ya había concluido el periodo de la cosecha fina en la región pampeana, proponía emular el mecanismo adoptado por el gobierno de la provincia de Buenos Aires, el cual para paliar las secuelas de la crisis económica optó por darle trabajo eventual a millares en "tareas de mejoramiento comunal" (5/3/83). En el final admonitorio, además, señalaba que una medida acertada consistiría en instaurar un seguro de desempleo financiado por los propios trabajadores para capacitar a los desocupados y darles créditos para que pudieran trabajar por cuenta propia, con lo cual demostraba que no abandonaba su intención de reconvertir a los obreros industriales.

La Nación también supo brindarle tratamiento editorial a los efectos inflacionarios de la política económica dictatorial, con la particularidad de abordar sus consecuencias como si afectaran a todos los sectores sociales por igual ${ }^{18}$. Ante estas, el diario apeló a lo que hemos dado en llamar una "equiparación inequitativa". El aparente contrasentido del concepto nos permite explicar cómo una de las estrategias comunicacionales empleadas, se basaba en subsumir a los trabajadores activos y desocupados dentro de un conjunto de actores e igualándolos como víctimas del mismo problema, como si cada uno de ellos se encontrara en las mismas condiciones para afrontarlo. En primer lugar, mediante el uso del subjetivema afectivo, señalaba que por entonces el nuestro era "un país ya sometido a una inflación 'inhumana". Además, la inclusión del adverbio "ya" no podía tener otro cometido que el de enfatizar la antigüedad de este fenómeno económico, siempre recalcado por el matutino, pero al cual ahora le añadía la condición de agobiante e intolerable para el colectivo unánime "todos los argentinos". Para dotar a su mensaje de mayor fuerza descriptiva, puntualizaba mediante subjetivemas evaluativos no axiológicos una a una a las víctimas: "asalariados y empleadores, agricultores, industriales y comerciantes, prestamistas y prestatarios, sin olvidar, por supuesto, al Estado y sus empresas, se encuentran trabados en una feroz lucha por el ingreso". El último actor mencionado, blanco permanente de su invectiva editorial, era ahora señalado por su debilidad ante

\footnotetext{
16 "El subsidio a los desocupados", op. cit.

17 “El subsidio de desempleo", La Nación, 5-3-1983, p. 6.

18 “Precios, salarios e inflación”, La Nación, 19-7-1983, p. 8.
} 
las presiones sindicales que lo convertían en artífice de la espiral inflacionaria, afirmando:"fuertes aumentos de salarios acordados en las denominadas 'miniparitarias' cuentan con el franco apoyo del ministro de Trabajo ${ }^{19 ”, ~ p u e s, ~ s e g u ́ n ~}$ enunciaba, sin disimular su malestar y apelando a subjetivemas axiológicos negativos, "la incapacidad de decir 'no' que aqueja al actual gobierno parece agravarse a medida que se acerca su fin" ${ }^{20}$. De lo cual se puede colegir que el matutino esperaba de las autoridades un comportamiento menos acuerdista y más reactivo frente a los reclamos sindicales.

Ahora bien, esta mirada crítica hacia el papel que cumplían los funcionarios públicos, desde la perspectiva del diario de los Mitre, no podía limitarse a los uniformados que ejercían el poder discrecional desde 1976. Por ello proponía a sus lectores una mirada retrospectiva con el objeto de dilucidar en qué momento los "grupos sociales de menores recursos" ${ }^{21}$ comenzaron a sufrir el embate inflacionario. Por supuesto que su veredicto no podía causar sorpresa alguna: como era habitual en esta columna, la "responsabilidad" fue atribuida de manera impersonal a la intervención estatal en la economía nacional. De este modo, omitía mencionar a Juan D. Perón como el protagonista de la acción a partir de 1945 y con subjetivemas axiológicos negativos empleados de manera irónica explicaba que "el principio de ese deterioro se dio, concreta y paradójicamente, con los gobiernos presuntamente favorecedores de las capas populares y generosos dispensadores de beneficios sociales"22. La construcción discursiva de la columna comenzaba manifestando su preocupación por la situación de los sectores más vulnerables de la sociedad, continuaba desplazándose a un tono irónico con el cual atribuía de manera paradojal el carácter de verdugos a los benefactores, y como corolario daba una pista incontrastable para su lectorado al puntualizar: "ese proceso histórico de cuatro décadas cumplidas ha sufrido recientemente una brusca aceleración, y en los doce meses últimos, en particular, ha llevado a situaciones francamente críticas" ${ }^{23}$.

Durante el mes previo a las elecciones, cuando en mayor cantidad de notas el matutino mencionaba los padecimientos que la crisis económica había producido en la sociedad, reafirmaría cuáles eran los límites que debían respetar los poderes públicos.

\footnotetext{
${ }^{19}$ Se trataba del abogado laboralista Héctor Villaveirán, quien "había sido director nacional del Servicio de Empleo (1952-1955) y subsecretario de Trabajo durante la dictadura de la Revolución Argentina (1966-1973)" (Canelo, 2016: 62). Como ministro de Trabajo acompañó al dictador general R. Bignone en toda su gestión, desde el 2 de julio de 1982 hasta el 9 de diciembre de 1983. Desde su cartera reactivó las negociaciones con los sindicalistas que el diario mencionaba recurriendo a la ironía de "miniparitarias", por no alcanzar el rango legal que tuvieron hasta el golpe de 1976.

20 “Precios, salarios e inflación”, op. cit.

21 “Problemas sociales y responsabilidad”, La Nación, 12-8-1983, p. 8.

22 Ibídem.

${ }^{23}$ Ibídem.
} 
Por ello, sentenciaba de manera admonitoria que para promover la producción industrial el Estado debía "asegurar un marco normativo alentador" ${ }^{24}$; obviando señalar que ese sector fue el principal perjudicado por el plan económico instaurado en 1976 por cuanto este valorizó las actividades financieras por sobre las productivas. En esta nota, además, el diario advertía sobre la necesidad de revertir la "inflación salvaje [y así] resolver este asunto fundamental no sólo para un feliz desenvolvimiento de la economía sino, a esta altura, para la posibilidad de una convivencia civilizada" 25 . En el aserto puede apreciarse que la inflación antes calificada con el subjetivema afectivo "inhumana" era ahora ponderada con otro de similar tenor: "salvaje", presentándola como par antagónico del sistema de vida que defendía la "tribuna de doctrina". De esta forma, al acercarse la fecha de los comicios, para los cuales no manifestó su preferencia por ningún candidato, La Nación reducía la posibilidad de la coexistencia social a una sola variable de la economía y puntualizaba de manera tácita que ese factor no solo podría perturbar la democratización del país, sino que también traería aparejado un escenario de confrontación encarnizada antisocial. Así, aunque no lo reconociera, colocaba al país en una situación similar a la que en marzo de 1976 había utilizado para justificar editorialmente "el gran cambio" que implicó la ruptura del sistema democrático.

\section{Las huelgas en 1983 y la democratización}

Como fue explicitado anteriormente, el diario de los Mitre entendía que durante el año 1983 el país vivía una situación de crisis -en el más amplio sentido del término-y en función de ello expresaría su preocupación editorial por el perjuicio sufrido por amplios sectores de la sociedad. Por cierto, del conjunto social serían los trabajadores conducidos por los sindicalistas quienes se manifestarían con acciones directas para reclamar por sus derechos. De ahí que el posicionamiento de este medio gráfico, de cara a las distintas medidas de fuerza ensayadas por los gremialistas, merezca un detenido examen que nos permita apreciar todas las variables enunciativas que puso en juego.

En primer término, diremos que si bien entre 1976 y 1982 La Nación se ocupó casi con exclusividad de aquellas medidas de carácter general convocadas por las centrales de tercer grado que actuaban como sucedáneas de la histórica CGT, a partir de la guerra

\footnotetext{
24 “Necesidad de una política para la industria”, La Nación, 7-9-1983, p. 8.

${ }^{25}$ Ibídem.
} 
de Malvinas y en consonancia con el incremento de la combatividad sindical, ${ }^{26}$ comenzaría a dar cuenta de distintos conflictos, sobre todo aquellos vinculados con los sectores que prestaban servicios a la población.

La editorialización de la extensa lista de huelgas comenzó con una crítica a la “Imprevista paralización del transporte" ${ }^{27}$, en la que descalificaba a los trabajadores de los subterráneos por "volver a la costumbre de hacer del público la víctima [sin comprender que los] servicios de ese carácter son obligaciones" ${ }^{28}$. Indudablemente, la apelación a la figura del retorno al pasado no cumplía otro fin que el de traer a la memoria de los lectores la alta conflictividad protagonizada por el sindicalismo tras la muerte de J. Perón hasta el golpe del 24 de marzo de 1976. Al mismo tiempo, llamaba la atención que ese actor había hecho de un incumplimiento una tradición, por lo cual predecía que la medida de fuerza vituperada no debía considerarse un hecho aislado, puesto que otras de similar índole se volverían recurrentes. Cambiando de interlocutor, se dirigiría de manera indirecta a los propios protagonistas para advertirles sobre la ineficacia de tales medidas, pues resultaba "difícil, en efecto, imaginar que las demandas de carácter salarial podrán ser satisfechas íntegramente, por más que las autoridades de que se trate procuren alcanzar ese objetivo"29. Así pues, mientras señalaba a los dirigentes gremiales que un "servicio" constituye una obligación, como si los demás empleos no tuviesen relaciones contractuales que imponen obligaciones, y alertaba a los lectores sobre el renacimiento de su victimización a manos de los sindicalistas, advertía a estos últimos sobre la inutilidad de sus reclamos; omitía enunciar que la condición de asalariado además de obligaciones otorga derechos, ${ }^{30}$ y si bien reconocía al PEN su carácter transitorio hasta la elección del futuro gobierno democrático y su "buena voluntad", no por ello dejaba de recordarle que los deberes de los funcionarios consistían precisamente en resolver problemas. Seguidamente, tras apelar al recurso de la concesión mediante el cual

\footnotetext{
${ }^{26}$ Godio y Palomino (1988: 53) consideran que "desde mediados de 1982 el sindicalismo desarrolló una activa movilización social aprovechando la descomposición del régimen, y con el objetivo de recuperar los niveles salariales fuertemente deteriorados durante la guerra debido al congelamiento de salarios impuesto por el ministro de Economía de Galtieri, y a la prosecución de la inflación en ese periodo. Una oleada de conflictos laborales en demanda de mejoras salariales, y como manifestaciones de repulsa al régimen que se derrumbaba, fue colocando a los dirigentes sindicales en el centro de la escena política y social".

27 “Imprevista paralización del transporte”, La Nación, 16-3-1983, p. 8.

${ }^{28}$ Ibídem.

${ }^{29}$ Ibídem.

${ }^{30}$ Cuestión que tratará la nota titulada "El derecho de huelga", La Nación, 8-6-1983, p. 8, en la cual, aun cuando reconocía su rango constitucional, reclamaba que se lo regulara para que los sindicatos no incurrieran en abuso o coerción, garantizando así el "ejercicio equilibrado de la libertad del trabajador". Al respecto, invocaba como principio de autoridad las iniciativas del parlamento nacional en 1958 y las del PEN en 1962 y octubre de 1975. Ya lo había propuesto ante el paro del 22/7/81 (Díaz, Giménez, 2016).
} 
reconocía que no se podía pedir a los sindicalistas que postergaran los reclamos hasta que asumieran las nuevas autoridades, empleaba una retórica con subjetivemas axiológicos negativos para predecir que "las huelgas imprevistas, los desórdenes sociales, la interrupción de los servicios esenciales son, siempre, y en todas partes, síntomas peligrosos y procedimientos equivocados. En este instante de la vida argentina, pueden convertirse, además, en ejercicios o ensayos con fines contrarios a la restauración de las instituciones republicanas" ${ }^{31}$. De esta manera, el diario planteaba categóricamente que el accionar sindical no solo perjudicaba a los usuarios sino que, además, lo descalificaba mediante subjetivemas axiológicos negativos tales como "peligroso" y "equivocado" pues podía impedir la democratización del país.

Desde una perspectiva valorativa similar, abordaría otra medida de fuerza, en este caso el paro general de actividades convocado por la CGT Azopardo ${ }^{32}$, al cual adheriría la CGT RA ${ }^{33}$. En efecto, en la nota titulada "Entre paros y marchas" ${ }^{34}$, además de condenar a ambos grupos sindicándolos de apelar a las medidas de fuerza para dirimir la disputa que mantenían por la primacía en la conducción del movimiento obrero, el diario sentenciaba que no aportaba "ningún saldo beneficioso para el país y sí muchos negativos". También ironizaba sobre el comportamiento del gobierno de facto, el cual, decía, se conformaba con "el mantenimiento del orden" y nada había hecho para paliar por lo menos el paro de transporte. Para La Nación, las apetencias personales de los gremialistas y la pasividad de los dictadores dejaban al país a merced de los primeros, presentados, en este caso, como par antagónico de "los argentinos [que] hemos aprendido a convivir también con los paros", pues si bien reconocía las razones sociales que permitían entenderlos, los desacreditaba presentándolos como contrarios al país. De este modo, la "tribuna de doctrina" que insistía en denunciar el comportamiento totalitario de los sindicalistas, en nombre de la unanimidad nacional enfatizaba: "es lamentable que el país entero deba seguir padeciendo estas dificultades, estas alteraciones de su ritmo normal de actividades, a pesar de que existe consenso absoluto sobre la inutilidad de las agitaciones y los conflictos sociales así enfocados" ${ }^{35}$. Estos subjetivemas evaluativos negativos, con los que valoraba a los dirigentes de ambas CGTs destinados a explicar que al ejercer el derecho de huelga consagrado en la Constitución Nacional, desafiaban su suspensión decretada por la dictadura desde 1976. Tal comportamiento, para el diario constituía "un acto de subversión en el sentido originario y jurídico-político de la palabra, pues aunque no se exprese mediante actos de violencia (...) el orden de la ley queda subvertido, es decir,

\footnotetext{
31 “Imprevista paralización del transporte" op. cit.

${ }^{32}$ Nombre adoptado por la CNT-20 durante la guerra de Malvinas (Abós, 1984: 89).

${ }^{33}$ La CGT RA (República Argentina) es la denominación que adoptó la CGT Brasil en enero de 1983. Su secretario general seguía siendo Saúl Ubaldini (Abós, 1984: 93).

34 "Entre paros y marchas", La Nación, 3-4-1983, p. 6.

35 Ibídem.
} 
reemplazado por otro poder que de un modo anómalo pero efectivo disputa al Estado su imperium". Para dotar su enunciado de mayor dramatismo, presentaba el cuadro de situación de un país que en lugar de transitar a la democracia lo hiciera a la anarquía y el caos, emplazando de manera tácita a los gobernantes de facto a ejercer el poder, pues "lo único que un Estado jamás puede entregar so pena de quedar desprovisto del elemento esencial que lo caracteriza a través de todos los tiempos". Y cerraba la columna induciendo a su público a colegir que el enemigo de la institucionalidad no era tan solo el sindicalismo, pues su comportamiento obedecía a la inacción, por no decir complicidad del PEN, refiriendo que ambos "están llevando demasiado lejos un juego que amenaza con escaparse de las manos" ${ }^{36}$. De esta forma el matutino anticipaba la enunciación de una suerte de pacto sindical-militar que, con otras características, denunciaría poco después el entonces candidato presidencial de la UCR Raúl Alfonsín. ${ }^{37}$ Con todo, el editorial omitía subrayar la contundente adhesión a la medida de fuerza concentrando su retórica en la deslegitimación social y jurídica del paro general, cuya ejecución solo había sido posible, a su entender, por la complicidad de los poderes públicos que permanecieron indiferentes, sugiriendo que el sindical se había convertido en un poder paralelo al que todavía ostentaban formalmente los uniformados.

Promediando el año, La Nación volverá a cuestionar al gobierno y a los gremialistas, en esta oportunidad negando que los motivos que los impulsaran a realizar las medidas de acción directa se debieran solo a razones reivindicativas. Por ello afirmaba que los "conflictos laborales por distintas causas - políticas o efectivamente gremiales- se han sucedido sin mayores interferencias de la autoridad de aplicación" ${ }^{38}$. En el mismo sentido, insistía en endilgarles a los sindicalistas, mediante subjetivemas axiológicos negativos, un comportamiento contrario al interés público, al estimar que su accionar "perturba y hasta puede causar daño a intereses superiores", con el agravante ya señalado de la ilegitimidad de ser decididas por "comisiones directivas [que] suelen arrogarse" la representación de los afiliados. Conviene aquí destacar que, para el diario, el "daño" no sería el provocado por la obturación del proceso democrático, sino el apoyo al innominado partido Justicialista, al afirmar de manera irónica: "raro es el gremio que en los órdenes nacional o provincial no amenaza con obstrucciones a la actividad productiva invocando causas que podrían tener mejor satisfacción en el diálogo, y son frecuentes en esos casos las declaraciones de corte netamente político,

\footnotetext{
${ }^{36}$ Ibídem.

${ }^{37}$ Efectivamente, el 25 de abril de 1983 el dirigente radical declarará la existencia de un pacto sindicalmilitar por el cual un triunfo del partido Justicialista les garantizaría impunidad a los jerarcas castrenses. Cabe anotar que esta denuncia no fue editorializada por los "socios" La Nación y Clarín, y sí por los "no socios" La Prensa y el Herald; véase Díaz, Giménez (2014). Por su parte, Ferrari (2013: 73) consigna erróneamente que "La Nación encontraba como positivo que un acuerdo entre sindicalistas y militares conformaba un freno para el gremialismo combativo".

38 “Huelgas e interés general”, La Nación, 27-6-1983, p. 6.
} 
que procuran ganar adhesiones a determinadas posturas partidarias" ${ }^{39}$. Aun cuando este parágrafo no aclaraba si el diálogo debía tener lugar entre trabajadores y patrones o entre los primeros y el Estado -pues así como tácitamente les negaba legalidad a los dirigentes, por cuanto sus mandatos habían concluido en medio de las intervenciones militares, tampoco aludía a la supresión de las discusiones paritarias como ámbitos propicios para el diálogo que reclamaba, cuando esta instancia de negociación entre patrones y empleados había sido suprimida desde 1976-, tal vez podamos inferir que el pretendido diálogo debía producirse entre empleados y empleadores, dado que el matutino aludiría nuevamente al ya sugerido "pacto sindical-militar" al afirmar:"en medio de esas relaciones distorsionadas entre las organizaciones laborales y el Gobierno quedan, lamentablemente, aprisionados los derechos de los demás, es decir, los de la gente común que integra la mayoría indiscutible de todo el país y no suele ser tenida en cuenta" ${ }^{40}$. En suma, el diario de la familia Mitre denostaba a los representantes del movimiento obrero al asociar su accionar con subjetivemas axiológicos negativos tales como: "conflicto", "interferencias", "amenaza", "obstrucciones", "relaciones distorsionadas", "perturbar" y "aprisionar derechos". Mientras que pocos meses atrás proponía la construcción del par antagónico conformado por el sindicalismo y la totalidad de los argentinos, ahora dicho par lo constituían una mayoría indiscutible victimizada por la acción de los sindicalistas y la inacción de la dictadura.

Como afirmamos con anterioridad, al acercarse el 30 de octubre de 1983 (fecha de los comicios) irían quedando de lado las predicciones agoreras de La Nación respecto de la obstaculización que podían significar las medidas de fuerza protagonizadas por los trabajadores, para ser explicadas como parte de su apoyo al innominado partido fundado por Juan D. Perón. No obstante, el diario también recurrió a otras estrategias discursivas para confrontar con el sindicalismo. Así como antes había anatematizado su rol al considerar que subvertía la legislación de facto, bien por defender intereses partidarios, bien por desinteresarse de los derechos del prójimo, ahora lo situaba actuando al margen de la razón, como si el sindicalismo respondiese a impulsos patológicos. Por ello no resulta extraño que en solo cuatro días haya incluido dos columnas en cuyos títulos apelaba a la figura del "límite" ${ }^{41}$ como metáfora de la

\footnotetext{
${ }^{39}$ Ibídem. Sin duda se trataba del Partido Justicialista; aunque ninguna de las dos centrales había adherido aún a este partido, la inmensa mayoría de sus dirigentes se encontraba afiliado a él y algunos eran autoridades del mismo.

${ }^{40}$ Ibídem.

${ }^{41}$ Según Núñez Erices (2010: 226), “el carácter moral del castigo y, más aún, la voluntad de poder que subyace, como diría Freud, pulsionalmente a esa moral supone la instalación de un límite, esto es, la delimitación de algo respecto a otra cosa. El castigar es un modo de delimitar, de trazar una línea divisoria entre el castigador y el castigado, entre lo legal y lo ilegal, entre los que ostentan poder y los que se someten a dicho poder. De este modo, el límite se sitúa espacialmente en ese entre, una frontera en la cual se pueden establecer diferencias morales entre lo que debe ser y lo que no debe ser,
} 
frontera entre lo racional y lo irracional. En el primer caso, el editorial "En el límite de lo absurdo" ${ }^{42}$ se valía de subjetivemas axiológicos negativos para endilgarles a los representantes de los trabajadores favorecer el caos imperante al responsabilizarlos del "panorama de conflictos sociales desatado en el país, junto con los de carácter político, judicial y económico, conforma un cuadro dentro del cual se producen situaciones inadmisibles para el sentido común o reveladoras del abandono de principios elementales de razonabilidad" ${ }^{43}$. En esta oportunidad, el reclamo del Sindicato Único del Personal de Aduanas oficiaría como acicate para que La Nación presentara al gobierno como rehén de los trabajadores al señalar que esa organización, "al comprobar que los paros iniciales no logran los resultados esperados, además de intensificar esas medidas, expresó en un comunicado 'la preocupación del gremio por la falta de reacción de la Secretaría de Hacienda'. Si se quiere una muestra de razonamiento absurdo, no hace falta más" ${ }^{44}$. Dado que se trataba de una actividad vinculada a servicios, la nota insistía en que "al gremio, por lo visto, no le preocupan, las consecuencias que sufren terceras partes absolutamente ajenas al conflicto" ${ }^{45}$, al tiempo que reafirmaba su contrato de lectura, remarcando el desdén manifestado por los perjuicios ocasionados al prójimo. El ardid de la señalización de una situación fronteriza se reiterará en otra columna, pero no en virtud del comportamiento de una organización gremial en particular, sino por el grado de generalización que ese accionar había alcanzado. Así, bajo el título "La Argentina en una hora límite" ${ }^{46}$, el matutino daba cuenta de un panorama caótico reinante que asociaba con la proliferación de los reclamos al aseverar: "la situación del país está llegando a extremos de desorden y confusión en el aspecto social y económico" ${ }^{47}$, para recurrir seguidamente a la figura de la metáfora con el propósito de endilgarle al actor sindical haber "desatado una oleada de indisciplina laboral, de petitorios multiplicados unos tras otros y de exigencias perentorias, incluyendo rebeliones francas de los cuerpos de seguridad en un alto número de provincias" ${ }^{48}$. En este caso, explicaba que el tácito pacto era posible merced a la transitoriedad de los funcionarios públicos y la irracionalidad gremial, subrayando: "este gobierno, precisamente, carece ya de toda oportunidad para resolver por sí solo ninguna cuestión de fondo como las que se plantean airadamente mediante paros, protestas callejeras 0 declaraciones

diferencias religiosas entre lo sagrado y lo profano, diferencias ontológicas entre lo que es y lo que no es, entre el ser y la nada, o bien legales entre lo que es lícito y lo que es ilícito, entre otras".

42 “En el límite de lo absurdo", La Nación, 17-9-1983, p. 6.

43 Ibídem.

${ }^{44}$ Ibídem.

45 Ibídem.

46 “La Argentina en una hora límite”, La Nación, 21-9-1983, p. 10.

${ }^{47}$ Ibídem.

${ }^{48}$ Ibídem. 
amenazantes $^{\prime 49}$. En lugar de afirmarse en la labor periodística de brindar información sobre las particularidades de cada sector que sufría una situación de injusticia, y por eso precisamente no era propiciador del conflicto sino que actuaba para resolverlo, la estrategia discursiva de La Nación escogía ignorar las causas de los reclamos y, lejos de atribuirlos a la autonomía sindical, recurría a la construcción de un actor fantasmagórico quien detrás de bambalinas manejaba los hilos de manera siniestra. Por eso, con los tonos propios del desasosiego hacía esta pregunta retórica:"hacia dónde vamos y qué o quiénes están conduciendo este desborde, cuando falta muy poco más de un mes para las elecciones que, presuntamente, el país entero consideró como el paso previo e ineludible para enfocar su destino por los carriles debidos" ${ }^{50}$. Lo llamativo de su mensaje es que después de haber presentado al sindicalismo como factótum del caos, ahora los equiparaba a simples marionetas inanimadas, con lo cual la necesidad de ponerle un límite al enemigo poderoso lo llevaría a valerse de la voz pasiva y, para acicatear a su lectorado, empleaba el recurso de la concesión, sugiriendo:

si se descarta la hipótesis de grupos ideológicos ${ }^{51}$ que procurarían aprovechar las dificultades del momento para trastornar esa marcha y conducirnos, a plazo más o menos breve, por las vías de la subversión y el caos hacia regímenes totalitarios de signo inequívoco, sólo quedaría como alternativa imaginar que la Argentina actúa como una sociedad alienada, mediante impulsos incoherentes e irracionales de sus diversos sectores componentes sin advertir cuánto hay de verdadero suicidio colectivo en ese accionar ${ }^{52}$.

En el remate de la columna, es dable observar la apelación a la metáfora organicista en su retórica editorial, es decir, una de las figuras de las que se valió para ejercer su rol hermesiano característico de los primeros años de la dictadura.

Al día siguiente del paro general convocado por ambas centrales de trabajadores, $L a$ Nación volverá a presentar el pacto sindical-militar como portador de la sinrazón y par antagónico de la unanimidad ciudadana en la siguiente afirmación: "el paro dispuesto por ambas centrales obreras era un verdadero sinsentido frente a un gobierno que nada puede hacer [...] pocas veces el país vivió anímicamente semejante sensación de efectiva parálisis. Pero ello no se debió a lo dispuesto por los grupos dirigentes gremiales que tomaron la decisión" ${ }^{\prime 53}$. Como puede apreciarse, para menoscabar la

\footnotetext{
49 Ibídem.

50 Ibídem.

${ }^{51}$ Desde marzo de 1976 el diario identificaría la ideología con la subversión contraponiéndolo con la doctrina occidental y cristiana que lo inspiraba (Díaz, Giménez, 2007).

52 "La Argentina en una hora límite", op. cit.

53 “La República que nació en Mayo", La Nación, 5-10-1983, p. 8. El título refiere al 25 de mayo de 1810, cuando se constituyó el primer gobierno patrio en Buenos Aires que desplazó al virrey Cisneros.
} 
representatividad de las dos CGTs las designaba como "grupos"; y si bien ahora no los presentaba como manipulados por fuerzas extrañas, no dejaba de adjudicarles la responsabilidad de operar como uno de los factores decisivos que coadyuvaban a una crisis que amenazaba con volverse irreversible, ya no para las autoridades castrenses, sino fundamentalmente para el futuro gobierno elegido por el pueblo, al sostener: "la Argentina vive horas de disolución institucional, sin que aparentemente lo adviertan quienes la gobiernan ni quienes aspiran a gobernarla dentro de muy poco" ${ }^{54}$. Con todo, pese a su desolación señalaba admonitoriamente: "hay un solo camino por seguir en los días que faltan y conduce, necesariamente, al ejercicio del sagrado deber del voto ciudadano (...) deben atender a ese llamado los magistrados y los funcionarios, los partidos políticos, los dirigentes gremiales y todos los sectores" ${ }^{155}$ (5/10/83). De lo cual se puede colegir que el matutino dejaba de lado el par antagónico construido inicialmente, que enfrentaba a los sindicalistas con la sociedad; el elaborado en segundo término que oponía a sindicalistas y militares con la sociedad; para pergeñar uno nuevo en el cual el diario escogía ponerse del lado de la racionalidad y colocar en el terreno de lo irracional o bien en la difusa región fronteriza, a los demás actores políticos que en su opinión obturaban la institucionalización del país.

Párrafo aparte merece el tratamiento brindado al único sector de trabajadores que fue incluido en más de un editorial por La Nación. Si el matutino consideraba inaceptable que los trabajadores que prestaban servicios en los subterráneos o el personal de aduanas adoptaran medidas de fuerza por perjudicar a los usuarios, ${ }^{56}$ resulta imaginable cuál era su opinión ante los docentes que seguían el mismo camino a causa de la postergación salarial que sufrían. Por eso editorializará este tópico resaltando la situación "fronteriza" de la medida de fuerza protagonizada por los educadores al aludir en su título a las "Razones y sinrazones de un paro docente" ${ }^{57}$,el cual fue

\footnotetext{
${ }^{54}$ Ibídem. En esas afirmaciones se puede apreciar que la narrativa de La Nación presenta una notable semejanza con la del historiador Hipólito Taine acerca de la movilización de masas durante la Revolución Francesa, a saber: "los contrabandistas, los traficantes ilegales de sal, los cazadores furtivos, los vagabundos, los mendigos y los convictos fugados, y cómo un año de hambruna incrementa su número. Todos son reclutas para las turbas [...]. Los campesinos se dejan convencer por los bandidos [...] a partir de entonces, son los nuevos líderes: ya que en toda turba son los más descarados y menos escrupulosos quienes marchan al frente y establecen el ejemplo de la destrucción [...]. En medio de una sociedad desintegrada, bajo un gobierno que ha pasado a serlo sólo en apariencia, se pone de manifiesto que se está gestando una invasión, una invasión de bárbaros que se completará mediante el terror, que ha comenzado con violencia y que, como la invasión de los normandos en los siglos X y XI termina con la conquista y la descomposición de toda una clase" (Laclau, 2010: 49-50).

55 Ibídem.

${ }^{56}$ Después de las elecciones esta prédica continuaría; por ejemplo, ante el trabajo a reglamento declarado por la Asociación del Personal Aeronáutico, el diario sentenciaba: "los usuarios son los únicos perjudicados y no tienen posibilidades de hacer nada" en "Conflicto en Aerolíneas", La Nación, 26-111983, p. 6.

57 “Razones y sinrazones de un paro docente”, La Nación, 9-6-1983, p. 8.
} 
declarado tan solo en dos municipios del conurbano bonaerense (aunque, merece aclararse, se trataba de los populosos Morón y La Matanza). Esta nota contenía, además, la particularidad de explicar que el problema del poder adquisitivo de los asalariados había comenzado en $1946,{ }^{58}$ y si bien consideraba que el mismo se había agravado en el periodo finidictatorial y por eso el reclamo docente tenía su fundamento, no por ello dejaba de fustigar la metodología empleada incluyéndola en la escalada "subversiva", 59 que venía denunciando. Haciendo uso nuevamente de subjetivemas negativos, La Nación descalificaba el accionar del trabajador docente, enumerando todos los actos que ponderaba contrarios a sus funciones específicas: "la obra del educador se resiente, en la esencia última de su naturaleza, si éste se alza contra el orden constituido y desconoce principios de respeto a la ley, si peticiona tumultuosamente, si exige en tono imperativo, si interrumpe su labor cotidiana y, sobre todo, si mezcla a los alumnos y a las familias en este tipo de manifestaciones" ${ }^{\prime 60}$. Resulta elocuente que la manipulación sufrida por los sindicalistas para subvertir el orden, que denunciaría en septiembre, se la asignara tres meses antes a los docentes, quienes, según la opinión del diario, manejaban a voluntad tanto a los alumnos como a sus progenitores, conduciéndolos a cometer hechos "subversivos". Como si tamaña imputación no alcanzara para descalificar a los trabajadores de la educación, también juzgaba su conducta atribuyéndole el agravante de propender a la defensa de una divisa partidaria. De igual modo que en los demás gremios, la sugerencia a pertenecer al partido peronista aparecía innominada, $y$, apelando a un subjetivema de connotación negativa les indicaba admonitoriamente que "las pasiones de las contiendas políticas y partidistas no deben llegar a las aulas ni deben ser asumidas desde la profesión del magisterio" ${ }^{61}$. En el remate de la columna, en tono amenazante, volvía a construir un par antagónico para recordar a los educadores que "el Estado y las familias confían a ese gremio la formación de sus hijos menores [y esta responsabilidad] podría ser usada con las consecuencias imaginables. Está en manos de los docentes y de sus dirigentes no caer en ese peligro" ${ }^{62}$. La segunda nota destinada a este sector durante 1983 no respondió a la realización de una medida de fuerza, sino que la motivó el aniversario de la muerte de Domingo F. Sarmiento, conmemoración el día del maestro ${ }^{63}$. En ella, además del tradicional elogio al

\footnotetext{
${ }^{58}$ Aun cuando por razones de organización del artículo hemos consignado con antelación que la responsabilidad de este fenómeno de la economía nacional fue editorializado por el matutino en "Problemas sociales y responsabilidad" el 12-8-1983, p. 8, no resulta casual que ese año la primera vez que le asignó a Perón la responsabilidad haya sido en una nota destinada a los docentes, quienes en su generalidad fueron un sector de los trabajadores menos identificados con él.

${ }^{59}$ Fue denunciada cuando ejercía el periodismo hermesiano, véase Díaz, Giménez (2007).

60 "Razones y sinrazones de un paro docente", op. cit,

${ }^{61}$ Ibídem.

62 Ibídem.

63 “Los docentes y las huelgas”, La Nación, 11-9-1983, p. 8.
} 
sanjuanino, se haría propicia la evocación para contrastar tácitamente el aporte de aquel con el comportamiento de sus "herederos". En esta oportunidad, La Nación se valió de la apelación a una edad de oro perdida para cuestionar la actividad de los sindicalistas en este sector, presentándolos mediante un particular par antagónico en el cual los maestros se convertían en víctimas y victimarios, como se desprende de este párrafo:

pocas veces como ahora esa escuela y los docentes se han visto tan afectados por huelgas o paros parciales. Lo que alguna vez, mucho tiempo atrás, pareció un imposible, se ha convertido en una costumbre o en una práctica que a nadie asombra: los paros docentes, la consiguiente interrupción de clases y hasta las manifestaciones en las cuales no faltan alumnos que colaboran en alcanzar carteles o vocear consignas ${ }^{64}$.

Pese a que la nota reconocía que estos trabajadores tenían las mismas necesidades y derechos que el resto de los miembros de su clase, señalaba que "la especial naturaleza de la función docente" ${ }^{65}$ debería inhibirlos de actuar como los demás asalariados, argumentando que en su carácter de educadores debían erigirse como ejemplo para sus educandos; en otros términos, enseñarles a aceptar pasivamente una situación de inequidad. La visión conductista de la educación, propia del matutino, se haría notar en el remate de la columna, donde manifestaba su temor ante la posible emulación del comportamiento "subversivo" de los docentes por parte de los alumnos: "frente a cualquier ocasión en que se crean o se sientan víctimas de alguna injusticia o procedimiento docente erróneo, podrían reaccionar apelando a métodos compulsivos o de alzamiento contra la autoridad, similares a los que ven practicar por sus maestros" ${ }^{\prime 66}$.

La tercera nota dedicada a este sector obedeció a un reclamo gremial de diferente índole y ejercido con distinta metodología que los anteriores. En efecto, la columna se ocupaba del accionar de uno de los gremios docentes (sin mencionarlo), el cual se había dirigido a las autoridades solicitando la creación de cargos con solo treinta alumnos. Frente a esta iniciativa, el diario se mostraría contemplativo, proponiendo a los lectores dos planos de análisis: el pedagógico, para el cual tomaba como principio de autoridad las corrientes educativas imperantes en el mundo occidental, en las cuales se señalaba que ese número de alumnos debía ser el máximo aceptable; y por otro lado, el orden económico-financiero, donde exponía la inconmensurable erogación que implicaba el sostenimiento del sistema educativo aun para los países desarrollados en los cuales se aplicaba ese precepto, agregando que si bien "la acción

\footnotetext{
${ }^{64}$ Ibídem.

${ }^{65}$ Ibídem.

${ }^{66}$ Ibídem.
} 
personal y directa del maestro o del profesor, en su labor tradicional ante un alumno o ante un curso, jamás será una imagen superada definitivamente" ${ }^{67}$, según sus estimaciones, mediante el uso de las tecnologías apropiadas esa circunstancia podía ser salvada. El cierre de la nota daba cuenta de su beneplácito con la participación de los gremios docentes en la resolución de esta problemática, instando a las autoridades a actuar con ellos de manera conjunta.

\section{Reflexiones finales}

El diario La Nación, justificó el golpe de Estado del 24 de marzo de 1976, la intervención a los sindicatos, la privación de la libertad de sus dirigentes y activistas, así como también la limitación de los derechos laborales, porque les atribuía, en consonancia con las autoridades del régimen, haber sido artífices de la decadencia institucional y el desorden social hasta esa fecha.

No obstante, hacia 1983 supo reconocer la situación de crisis económica del país y las consecuencias sociales que perjudicaban a distintos sectores. Al respecto, sus notas afirmaban que afectaba a todos por igual, proponiendo con ello una suerte de equiparación inequitativa. Inicialmente, si bien los reclamos de los trabajadores le resultaban comprensibles, cuestiona la metodología de los sindicalistas, a quienes en todo momento presenta escindidos de sus bases y perjudicando a terceros. Impulsa así su deslegitimación, tanto al negarles la representación de los trabajadores como al señalar que actúan en defensa de intereses personales perturbando a la sociedad. Para ello apelaba a subjetivemas valorativos negativos tales como: "huelgas imprevistas", "desórdenes sociales", "interrupción de servicios esenciales", "síntomas peligrosos", "procedimientos equivocados", "contrarios a la restauración de las instituciones republicanas", "conflicto", "interferencias", "perturbar", "amenaza”, "obstrucciones", "relaciones distorsionadas", "aprisionar derechos", "airadamente", "amenazantes".

De todos modos, no atribuye a los sindicalistas la responsabilidad exclusiva de su accionar al dar a entender el funcionamiento de un tácito pacto sindical-militar en el cual la dictadura en retirada, en lugar de ejercer su autoridad, toleraba la acción sindical cual poder paralelo que subvertía el orden institucional. En este sentido, el diario descalifica sus medidas mediante los siguientes subjetivemas axiológicos negativos: "acto de subversión", "orden subvertido", "modo anómalo", "disputa al Estado su imperium", "rebeliones francas", "grupos ideológicos", "vías de la subversión y el caos hacia regímenes totalitarios de signo inequívoco".

\footnotetext{
67 “No más de treinta alumnos”, La Nación, 16-10-1983, p. 10.
} 
Otra variante que robusteció su estrategia discursiva fue la utilización de la "metáfora organicista" al sugerir que los sindicalistas actuaban al borde de la racionalidad, connotándolos con subjetivemas negativos como: "límite de lo absurdo", "abandono de razonabilidad", "razonamiento absurdo", "hora límite", "extremos de desorden", "sociedad alienada", "impulsos incoherentes e irracionales", "verdadero suicidio colectivo", "inadmisibles para el sentido común".

Si bien el diario examinado descalifica las medidas de fuerza en general, pone especial atención en las realizadas por el gremio docente. Sus paros, al afectar a terceros fueron duramente denostadas mediante subjetivemas axiológicos negativos: "afectados por huelgas", "costumbre", "interrupción de clases", "manifestaciones", "alumnos que colaboran en alcanzar carteles o vocear consignas". Pero, dada la misión formativa que le compete a los trabajadores de la educación, La Nación exacerbó la atribución de comportamiento subversivo que también le endilgó al resto de la clase trabajadora. Por caso, reputaba que con su accionar "la obra del educador se resiente", "se alza contra el orden constituido", "desconoce principios de respeto a la ley", "peticiona tumultuosamente", "exige en tono imperativo", "interrumpe su labor cotidiana", "mezcla a los alumnos y a las familias en este tipo de manifestaciones".

El diario denunció con contundencia los propósitos políticos que inspiraban a los sindicalistas, y si bien eludía nominar a qué agrupamiento partidarios se refería, puede colegirse que era el Justicialismo pues la mayoría de los dirigentes sindicales adhería a ese partido. En este orden, las medidas de fuerza fueron vinculadas con las "pasiones de las contiendas políticas y partidistas".

En síntesis, a medida que se acercaba la elección general del 30 de octubre de 1983 que consagraría al futuro presidente democrático de la República, la columna institucional del diario La Nación, mediante las variantes presentadas en su estrategia discursiva editorial sostuvo, coherente con su historia, un rechazo sin fisuras al accionar del sindicalismo argentino. Sí bien no hizo una utilización asidua de recursos como el principio de autoridad, la concesión, la ironía y los enlaces positivos, si se pudo apreciar una interesante apelación al par antagónico. En su empleo se pudo identificar tres etapas diferenciadas. Inicialmente presentaba al sindicalismo como uno de los polos de un par antagónico en confrontación con otro polo constituido por el conjunto de la sociedad. En segundo término, al polo sindical se sumaría la dictadura militar en un acuerdo tácito, mientras que el otro polo seguía conformado por el conjunto de la comunidad. Por último, el par antagónico se conformaría con el sindicalismo y los demás actores políticos que toleraban su accionar rivalizando con el polo en el que se situaba el diario que motiva esta indagación. Finalmente, La Nación entendía que la profusión de huelgas llevaría al país al borde del abismo tornándose ingobernable, no solo para el régimen castrense sino fundamentalmente para las autoridades elegidas 
democráticamente, con lo cual, el accionar del sindicalismo, hipotecaba el futuro institucional de la Argentina.

\section{Referencias bibliográficas}

ABÓS, A. (1984): Las organizaciones sindicales y el poder militar (1976-1983), Buenos Aires, CEAL.

BORRAT, H. (1989): El periódico, actor político, Barcelona, Gustavo Gili.

CANELO, P. (2016): "La militarización del Estado durante la última dictadura militar argentina. Un estudio de los gabinetes del Poder Ejecutivo Nacional entre 1976 y 1983" en doi:dx.doi.org/10.7440/histcrit62.2016.03. Disponible en Internet (2908-2017):

http://www.scielo.org.co/pdf/rhc/n62/n62a04.pdf

CONADEP (2012): Nunca Más. Informe de la Comisión Nacional sobre la Desaparición de Personas, Buenos Aires, Eudeba.

DELICH, F. (1983): "La metáfora de la sociedad enferma" en La Argentina en Transición, Buenos Aires, Crítica y Utopía, № 10/11, pp. 11-31.

DíAZ, C. (2011): "La Nación y Clarín frente a la violencia política 1976-1980. Dos casos de periodismo hermesiano", en Saborido, J. y Borrelli, M. (compiladores), Voces y silencios: la prensa argentina y la dictadura militar (1976-1983), Buenos Aires, Eudeba, pp. 153-180.

DÍAZ, C. y GIMÉNEZ, M. (2007): “La Batalla editorial de La Nación: de la tribuna doctrinaria al pragmatismo político (1976-1979)", en XI Jornadas Interescuelas/departamentos de Historia, Tucumán, Facultad de Filosofía y Letras, Universidad Nacional de Tucumán, CD ROM Ponencias.

DÍAZ, C. y GIMÉNEZ, M. (2014): “La Prensa y el Herald y su particular construcción de un imaginario sobre el sindicalismo en la transición democrática argentina (19821983)" en Tercer Milenio. Revista bianual de la Escuela de Periodismo, Universidad Católica del Norte, no 27, septiembre de 2014. Disponible en Internet (27-08-2017): http://www.periodismoucn.cl/tercermilenio/2014/09/laprensa-y-el-herald-y-su-particular-construccion-de-un-imaginario-sobre-elsindicalismo-en-la-transicion-democratica-argentina-1982-19831/ 
DÍAZ, C. y GIMÉNEZ, M. (2016): “La Nación y el sindicalismo. La construcción editorial de un imaginario negativo" en Tram[p]as de la comunicación y la cultura, no 78, marzo de 2016, pp. 65-90. Disponible en Internet (28-08-2017): http://www.revistatrampas.com.ar

DÍAZ, C., GIMÉNEZ, M. Y PASSARO, M. (2002): “La Nación y la construcción del 'gran cambio'”, en Díaz, C., La cuenta regresiva, Buenos Aires, La Crujía, pp. 95-113.

DIÉGUEZ, H., GERCHUNOFF, P. (1984): "La dinámica del mercado laboral urbano en la Argentina, 1976-1981" en Desarrollo Económico-Revista de Ciencias Sociales, Buenos Aires, Vol. 24, № 93, pp. 4-40.

DUCROT, O. (1989): El decir y lo dicho, Buenos Aires, Hachette.

FERNÁNDEZ BERDAGUER, L. (2007): "Las transformaciones en el mundo del trabajo", en Camou, A., Tortti, M. y Viguera, A. (coordinadores), La Argentina democrática: los años y los libros, Buenos Aires, Prometeo, pp 179-199.

FERRARI, G. (2013):1983 el año de la democracia, Buenos Aires, Planeta.

GIMÉNEZ, M. (2015): "El hito de la guerra de Malvinas y el futuro de la Argentina en los editoriales de La Nación", en XV Jornadas Interescuelas/departamentos de Historia Actas, Comodoro Rivadavia, Facultad de Humanidades y Ciencias Sociales, Universidad Nacional de la Patagonia San Juan Bosco (UNPSJB).

GODIO, J. Y PALOMINO, H. (1988): "El movimiento sindical argentino hoy: historia, organización y nuevos desafíos programáticos" en Godio, J., Palomino, H. y Wachendorfer, A., El movimiento sindical argentino (1880-1987), Buenos Aires, Puntosur, pp. 15-109.

KERBRAT-ORECCHIONI, C. (1997): La enunciación. De la subjetividad en el lenguaje, Buenos Aires, Edicial.

LACLAU, E. (2010): La razón populista, Buenos Aires, Fondo de Cultura Económica.

MAINGUENEAU, D. (1989): Introducción a los métodos de análisis del discurso, Buenos Aires, Hachette.

NÚÑEZ ERICES, G. G. (2010): “El concepto de límite y poder tras la figura del castigo. Una lectura de las sociedades modernas occidentales" en Derecho $y$ Humanidades, № 16, vol. 1, pp. 223-260.

http://www.derechoyhumanidades.uchile.cl/index.php/RDH/article/view/16013 (consultado 20/8/2017, 8:26 hs.) 
SCHVARZER, J. (1998): Implantación de un modelo económico. La experiencia argentina entre 1975 y el 2000, Buenos Aires, A-Z editora.

SIDICARO, R. (1993): La política mirada desde arriba, Buenos Aires, Sudamericana.

VERÓN, E. (2005): Fragmentos de un tejido, Barcelona, Gedisa.

\section{Fuentes}

Diario La Nación (Argentina). Consultado en la Hemeroteca de la Legislatura de la Provincia de Buenos Aires- Argentina. 